\title{
A propriedade intelectual como vantagem competitiva na Ásia
}

\section{Intellectual property as a competitive advantage in Asia}

\author{
Guilherme Aparecido da Silva Maia \\ Rosemary Matias ${ }^{2}$ \\ Ademir Kleber Morbeck de Oliveir ${ }^{3}$
}

\begin{abstract}
RESUMO
A Ásia é a região mais dinâmica do mundo na atualidade e seu sistema de proteção de conhecimento varia conforme a região, economia e cultura dos países. Deste modo, o objetivo deste trabalho foi compreender qual a relevância da propriedade intelectual no desenvolvimento das seguintes nações: Camboja, China, Índia, Malásia, Singapura, Tailândia e Coreia do Sul. Material e Métodos conforme TRANFIELD et al. (2003) adaptado de CLARK e OXMAN (2001) Os resultados alcançados indicaram que o desenvolvimento econômico dos países está estreitamente relacionado à proteção do conhecimento. O Camboja, por exemplo, apresentou baixíssimo nível de proteção, com 6 patentes no período de 2007 a 2016 e isso se refletiu no PIB, que em 2007 foi de 31,9 e 2016, 54,6; por outro lado, Singapura em 2007 tinha 7.728 patentes e um PIB de 314,0 e, em 2016, 6.722 patentes e PIB de 456,7. Dos países estudados, apenas a China conseguiu consolidar um quadro de patentes domésticas superior as externas, fazendo a diferença em seu desenvolvimento econômico. Conclui-se que o nível de desenvolvimento de um país está estreitamente relacionado ao seu desenvolvimento tecnológico e sistema de proteção do conhecimento, especialmente as patentes domésticas.
\end{abstract}

\section{PALAVRAS-CHAVE:}

Desenvolvimento, inovação tecnológica, patente.

\begin{abstract}
Asia is the most dynamic region in the world today and its knowledge protection system varies according to the region, economy and culture of the countries. Thus, the objective of this work was to understand the relevance of intellectual property in the development of the following

\footnotetext{
${ }^{1}$ Graduado em Direito, especialista em Inovação e Difusão de Tecnologias, mestre e doutor em Meio Ambiente e Desenvolvimento Regional, na linha de pesquisa sobre Proteção Jurídica do Conhecimento (Propriedade Intelectual e Direitos de Autor). Sua linha de trabalho envolve Gestão de Projetos, Empreendedorismo e Inovação, Gestão Pública, Direito do Ambiente e Direito de Propriedade Intelectual, tanto no ensino universitário, consultorias e treinamentos empresariais. Atualmente é docente da Estácio de Sá, Campo Grande-MS.

${ }^{2}$ Possui Graduação em Licenciatura Plena em Química pela Universidade Federal de Mato Grosso do Sul (1988) e mestrado (1995) e doutorado (2010) em Química pela Universidade Estadual de Maringá - UEM. Professora adjunta do Programa de Pós-Graduação em Meio Ambiente e Desenvolvimento Regional. Pesquisador CNP2 na área de Ciências Ambientais: química ambiental e Produtos naturais e na Graduação atua nos cursos de Ciências Biológicas e Agronomia.

${ }^{3}$ Possui graduação em Ciências Biológicas pela Universidade Federal de Mato Grosso do Sul (1989), mestrado em Ecologia e Recursos Naturais pela Universidade Federal de São Carlos (1993) e doutorado em Ciências, área de concentração em Ecologia e Recursos Naturais pela Universidade Federal de São Carlos (1996). Atualmente é professor da Universidade Anhanguera-Uniderp. Tem experiência na área de Ecologia, com ênfase em Ecologia de Ecossistemas, atuando principalmente nos seguintes temas: ecologia de ecossistemas, Pantanal, etnobiologia, sementes e análise de crescimento de espécies nativas. Bolsista de Produtividade em Pesquisa 1D.
} 
countries: Cambodia, China, India, Malaysia, Singapore, Thailand and South Korea. Material and Methods According to TRANFIELD et al. (2003) adapted from CLARK and OXMAN (2001) The results indicated that the economic development of countries is closely related to the protection of knowledge. Cambodia, for example, presented a very low level of protection, with 6 patents in the period from 2007 to 2016 and this was reflected in the GDP, which in 2007 was 31.9 and 2016, 54.6; On the other hand, Singapore in 2007 had 7,728 patents and a GDP of 314.0 and, in 2016, 6,722 patents and GDP of 456.7. Of the countries surveyed, only China has been able to consolidate a domestic patent framework that is superior to external ones, making a difference in its economic development. It is concluded that the level of development of a country is closely related to its technological development and knowledge protection system, especially the domestics patents.

\section{KEYWORDS:}

Development, tecnologic innovation, patent.

\section{INTRODUÇÃO}

A discussão sobre propriedade intelectual, principalmente entre os países do Sudoeste da Ásia, mais China e Índia, considerada a região mais dinâmica do mundo contemporâneo, é importante, uma vez que a região se sobressai em relação aos demais continentes. O objetivo é investigar não apenas a condição atual dos regimes de propriedade intelectual em países que variam em tamanho econômico, do Camboja ao Japão e, na população, do Laos a China, mas também descrever as fontes históricas dessas leis e instituições; as realidades da aplicação da propriedade intelectual no mercado, e, as infraestruturas políticas, econômicas, educacionais e científicas que sustentam e direcionam o investimento em atividades inovadoras.

$\mathrm{Na}$ Ásia, o impacto das regras de propriedade intelectual e das instituições sobre inovação e crescimento econômico pode variar de uma região para outra, como por exemplo, Singapura e Malásia. Mas por que as infraestruturas científicas e tecnológicas de Singapura catapultaram essa nação na lista de países com maior Produto Interno Bruto (PIB), per capita, em todo o mundo, enquanto as infraestruturas da Malásia não conseguiram o mesmo êxito? (DREXL et al., 2009). Vale lembrar que ambas foram colonizadas pelos britânicos nas mesmas condições. 
Uma hipótese é que a proximidade geográfica entre determinados países poderia ter influenciado essa diferença de desenvolvimento. Será que o ingresso de bens pirateados de um país economicamente mais desenvolvido para um vizinho menos desenvolvido que não possui instalações industriais, por exemplo, da Tailândia para o Laos, bloqueia as perspectivas do segundo país de desenvolver suas próprias infraestruturas de inovação? (DREXL et al., 2009).

A região que compreende Tailândia, Myanmar (antiga Birmânia) e Laos (Figura 1), ficou conhecida nos séculos XIX e XX como Triângulo de Ouro, devido a riqueza gerada pelo ópio e pelo contrabando em uma região montanhosa e coberta pela selva que facilita a prática de atos ilícitos, com localização geográfica em muito favoreceu esse tipo de comércio (DREXL et al., 2009).

Figura 1. O Triângulo do Ouro dos séculos XIX e XX, onde as montanhas da região da Tailândia, Myanmar e Laos formavam o caminho do ópio e do contrabando de mercadorias.

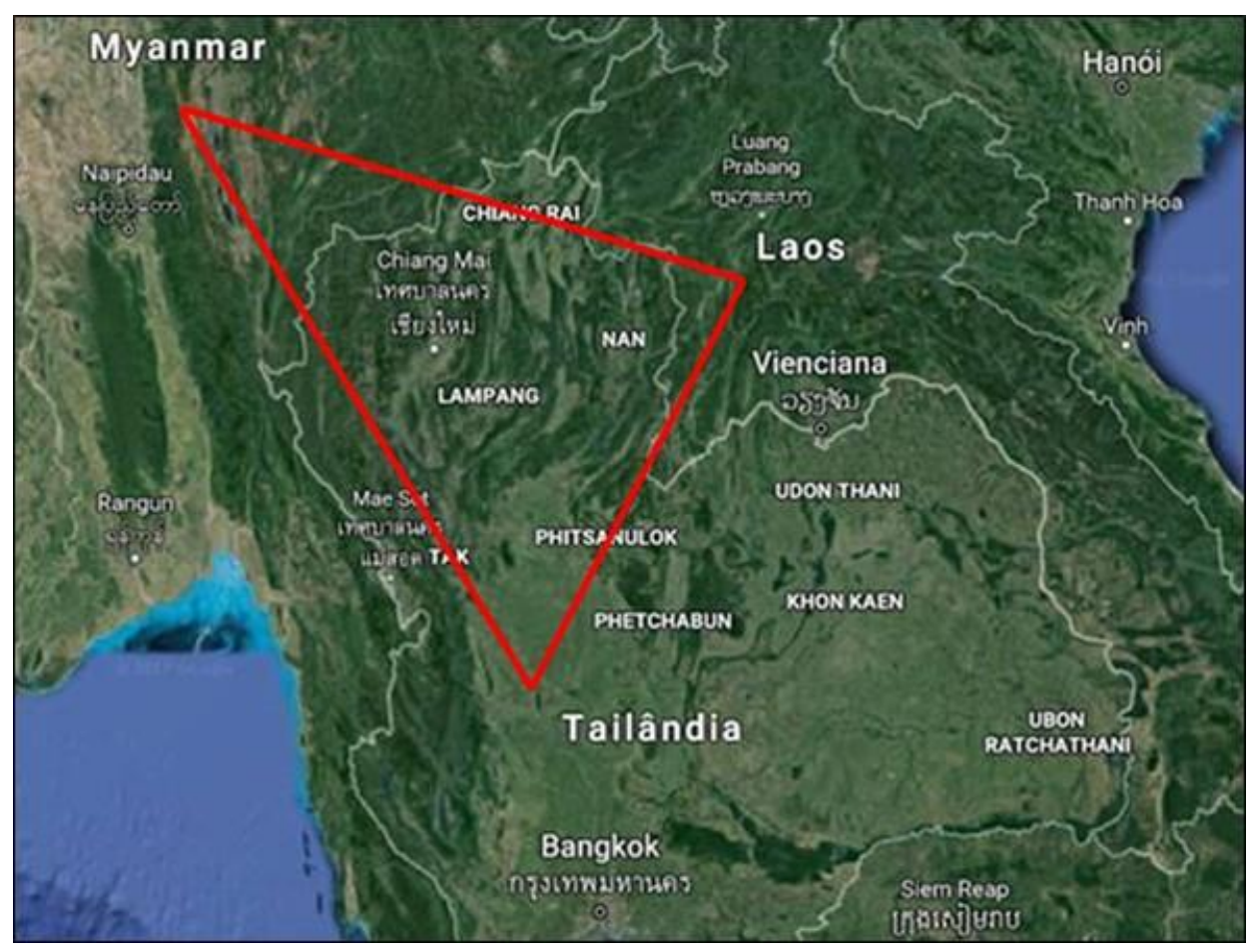

Fonte: Google Maps (2018).

Em períodos mais recentes, desde a década de 1960, a Ásia experimentou um crescimento impressionante, apenas desacelerando no final dos anos 1990. As taxas de crescimento impressionam: no Camboja, por exemplo a economia cresceu 13\% em 2005 e 10\%, 2006, enquanto a economia chinesa cresceu consistentemente em cerca de $10 \%$ nesse período. 
O Japão é positivo em quase todos os indicadores econômicos, tendo se destacado em PIB e renda per capita dos demais países asiáticos na década de 1960. A Coreia do Sul também é um exemplo de desempenho tecnológico e econômico. A China também é um caso de sucesso na economia, embora com algumas particularidades.

Embora o seu PIB tenha disparado desde a década de 1990, passando pelos anos 2000, a renda per capita permanece baixa (Figuras 2 e 3) (DREXL et al., 2009).

Figura 2. Crescimento do PIB da China entre os anos de 2008 a 2016.

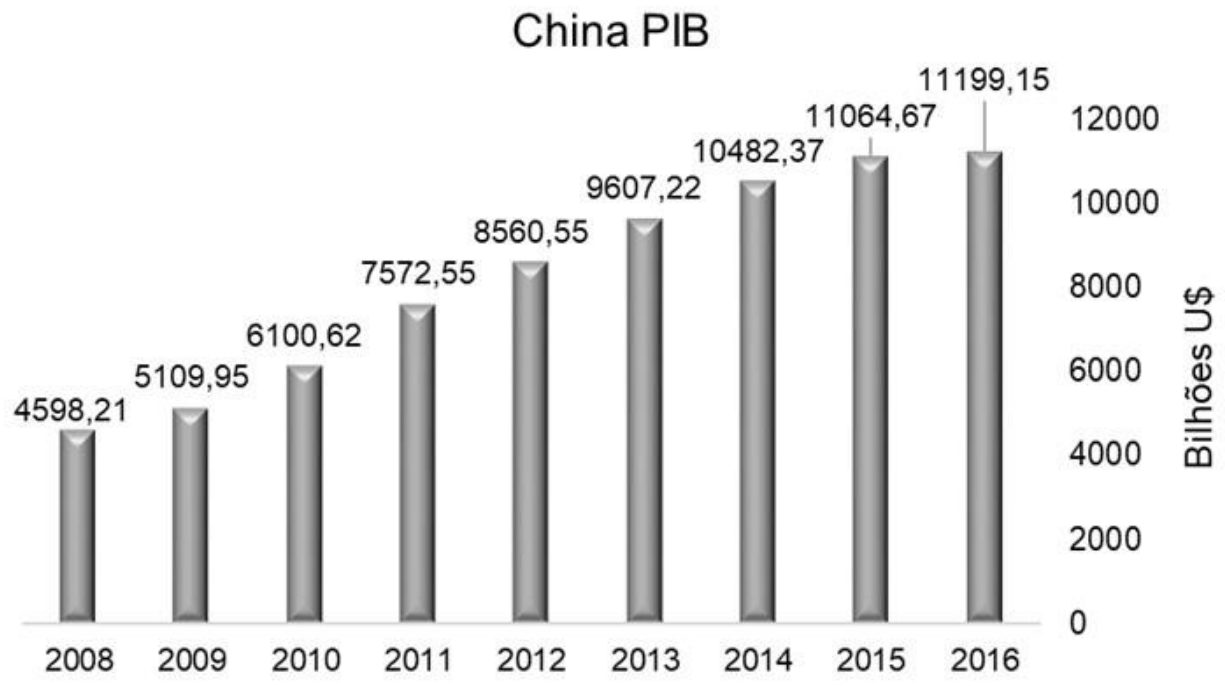

Fonte: Adaptado de Trading Economics (2018).

$\mathrm{Na}$ Ásia como um todo ocorreu um aumento nas exportações, incluindo uma crescente participação de produtos de alta tecnologia. Enquanto apenas três economias asiáticas (Japão, Taiwan e Coréia do Sul) estavam na lista das dez maiores empresas exportadoras de tecnologia (Top Ten High-Tech Exporters), em 1986, sete economias asiáticas (Japão, China, Coréia do Sul, Hong Kong, Taiwan, Cingapura e Malásia) dominavam a lista em 2005 (DREXL et al., 2009).

Mas, afinal, quais fatores contribuíram para esse crescimento em inovação?

Figura 3. Renda per capita da China de 2010, com previsão até o ano de 2021. 


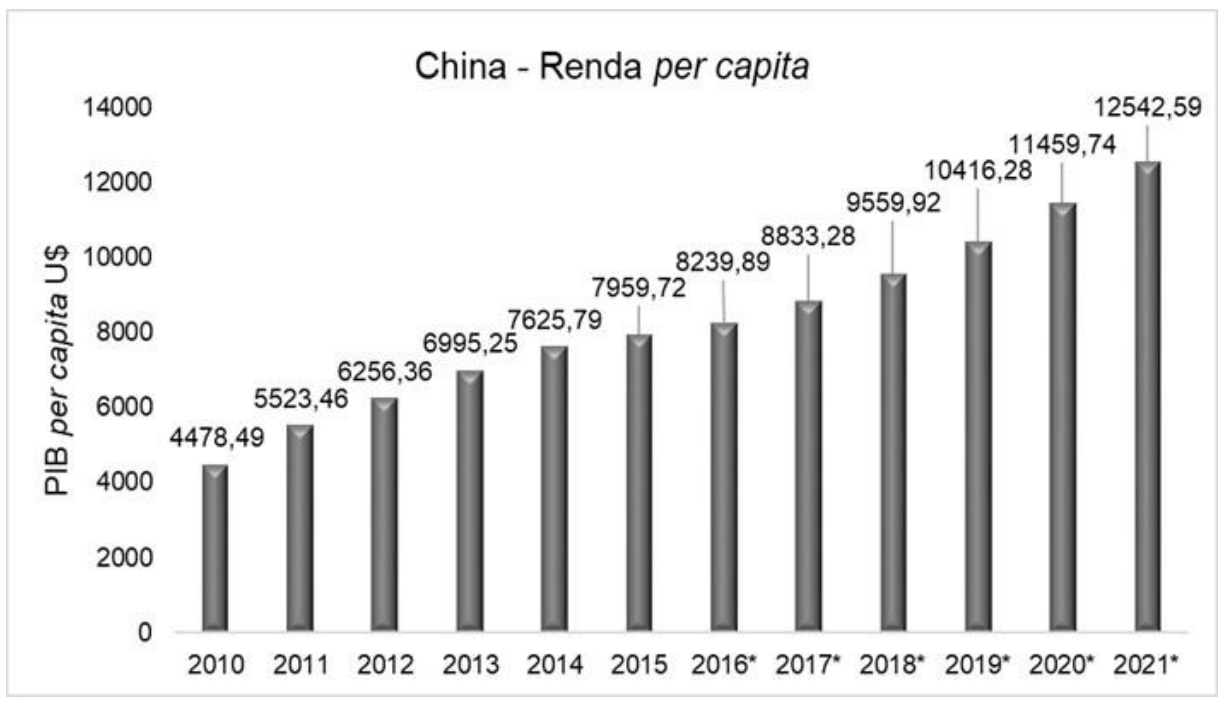

Fonte: Adaptado de Trading Economics (2018).

\section{MATERIAL E MÉTODOS}

A metodologia aplicada para este trabalho a Revisão Sistemática, que ocorreu em três estágios: planejamento, condução e disseminação, conforme TRANFIELD et al. (2003) adaptado de CLARK e OXMAN (2001), conforme estratégia de busca apontada no Quadro 1.

Quadro 1. Estratégia de busca das publicações com foco em propriedade intelectual e direitos de autor

\begin{tabular}{|c|l|}
\hline Estratégias de busca & \multicolumn{1}{l|}{ Palavras-chave e combinação de termos } \\
\hline Busca 01 & Proteção do conhecimento e propriedade intelectual \\
Busca 02 & Convenções internacionais e propriedade intelectual \\
Busca 03 & Direitos de autor e propriedade intelectual \\
Busca 04 & Copyrights and Intellectual Property \\
Busca 05 & Intellectual Propriety in Asia \\
Busca 06 & Intellectual Propriety and Asia and Netherlands \\
Busca 07 & Copyrights and Intellectual Property in Asia \\
\hline
\end{tabular}

Fonte. Adaptado de Silva (2016). 


\section{RESULTADOS E DISCUSSÃO}

Na avaliação de DREXL et al. (2009), o investimento em inovação é o que destaca a Ásia dos demais países e continentes. Para o autor, essa inovação somente é possível porque a região detém a totalidade dos direitos de propriedade intelectual para organizar investimentos em inovação relacionados às patentes de invenção e de design e modelos de utilidade; registro de direitos atorais; marca comercial; e, concorrência desleal. Tudo isso, acompanhado de administração sofisticada e vigorosa. Os países menos desenvolvidos dependem de versões geralmente menos robustas desses mecanismos e, em alguns casos, evitam as patentes de invenções completamente. Porém, à medida que os países menos desenvolvidos evoluem economicamente, o primeiro passo é investir e sofisticar seus sistemas de propriedade intelectual (DREXL et al., 2009).

$\mathrm{Na}$ Ásia, a valorização da propriedade intelectual está estreitamente relacionada com os direitos de propriedade privada e produção industrial dentro dos limites de suas fronteiras. Esse foi um processo histórico, que demanda uma análise do elo que existe entre a propriedade privada e intelectual. Para compreender essa interface, basta analisar e mapear o avanço da propriedade privada em estágio inicial e comparar com o atual. Em seu estágio economicamente mais primitivo, a região não possuirá nem as instalações industriais necessárias para fabricar bens em quantidades comerciais, tampouco as instituições de propriedade intelectual para impedir a reprodução não autorizada (DREXL et al., 2009).

Mesmo em tempos do Acordo TRIPS (Aspectos dos Direitos de Propriedade Intelectual Relacionados com o Comércio) e outras obrigações internacionais baseadas no comércio, as leis e instituições de propriedade intelectual podem existir nos livros, mas gozam de pouco ou nenhum efeito prático no mercado. Para dar um exemplo, embora as leis de propriedade intelectual tenham estado em vigor no Camboja desde 2001, nem as atividades de execução nem as indústrias imitativas evoluíram até o momento (DREXL et al., 2009). 


\subsection{A propriedade intelectual no Camboja e seus países vizinhos}

Segundo GANEA (2009a), a propriedade intelectual tem um histórico recente no país. A legislação de propriedade intelectual teve início em 2001, com a promulgação do Decreto Real sobre marcas, nomes comerciais e atos de concorrência desleal (completada pelo SubDecreto n. 46 que regulamenta a implementação da lei de marcas, nomes comerciais e atos de concorrência desleal, de julho 2006).

Essa recente adaptação ao Sistema de Proteção ao Conhecimento no Camboja refletiu nos baixíssimos indicadores de patentes no País (Quadro 2).

Em 2007, o quadro legal foi completado pela lei sobre patentes, certificados de modelos de utilidade e desenhos industriais, por meio de uma Declaração sobre a concessão de procedimentos de patentes e certificados de modelo de utilidade. Embora o Camboja não seja signatário da Convenção de Berna, ele promulgou a sua lei de direitos do autor e direitos conexos em janeiro de 2003, bem como, ainda, um Regulamento Especial, de julho de 2005, sobre a proteção da violação dos direitos morais (BNGLEGAL, 2012).

Quadro 2. Relação entre patente, marca e desenho industrial, em milhares, e o PIB, em milhões, do Camboja no período de 2007 a 2016

\begin{tabular}{|l|r|r|r|r|}
\hline \multicolumn{5}{|c|}{ Pl (Doméstica + Externa, Incluindo Regional) e Economia } \\
\hline Ano & Patente & Marca & Desenho & PIB (Constante 2011 US\$) \\
\hline 2007 & & 553 & 4 & 31.90 \\
2008 & & 582 & 5 & 34.04 \\
2009 & & 493 & 4 & 34.07 \\
2010 & & 7 & 36.10 \\
2011 & & 936 & & 38.65 \\
2012 & & 938 & 3 & 41.48 \\
2013 & 1 & 1.036 & 51 & 44.56 \\
2014 & 5 & 1.408 & 23 & 47.71 \\
2015 & & & & 51.07 \\
2016 & & & & 54.58 \\
\hline
\end{tabular}

Fonte: WIPO (2016).

A integração do Camboja no quadro da Convenção Internacional de Propriedade Intelectual também começou relativamente tarde. Somente em abril de 1995, o país formalizou sua adesão à WIPO e, em setembro de 1998, aderiu à Convenção de Paris (WIPO, 2018). 
Segundo DREXL et al. (2009), houve um estágio em que os países da Ásia conseguiram melhorar seu parque industrial e ampliar a sua capacidade imitativa; porém, ainda faltava mecanismos efetivos de imposição para fechar as fronteiras para a entrada de cópias não autorizadas. Um bom exemplo desse contexto é a Malásia, um dos maiores exportadores mundiais de software pirateado. Nesse país existe a capacidade de reproduzir, porém a capacidade de proteger ainda é ilegítima. No entanto, mesmo assim, com todas as dificuldades, a Malásia ainda apresenta melhores números significativos de depósito de patentes, com um aumento do número de patente refletindo um aumento do aumento do PIB no País (Quadro 3).

Quadro 3. Relação entre patente, marca e desenho industrial, em milhares, e o PIB, em milhões, da Malásia no período de 2007 a 2016

\begin{tabular}{|l|r|r|r|r|}
\hline \multicolumn{5}{|c|}{ Pl (Doméstica + Externa, Incluindo Regional) e Economia } \\
\hline Ano & Patente & Marca & Desenho & PIB (Constante 2011 US\$) \\
\hline 2007 & 1,177 & 17,465 & 2,256 & 550.74 \\
2008 & 1,361 & 17,126 & 2,537 & 569.03 \\
2009 & 1,812 & 19,057 & 2,039 & 554.65 \\
2010 & 1,937 & 20,747 & 1,531 & 593.37 \\
2011 & 1,948 & 18,490 & 1,979 & 624.79 \\
2012 & 1,975 & 21,887 & 1,721 & 658.99 \\
2013 & 2,299 & 23,763 & 1,541 & 689.92 \\
2014 & 2,661 & 23,358 & 1,218 & 731.39 \\
2015 & 2,348 & 24,233 & 884 & 767.74 \\
2016 & 1,963 & 29,283 & 1,149 & 800.28 \\
\hline
\end{tabular}

Fonte: WIPO (2016).

Consequentemente, o aumento da propriedade intelectual aumentou a riqueza do país; tal situação não ocorreu em Myanmar (Quadro 4), ficando evidenciado que o desenvolvimento econômico de um foi mais impulsionado pela proteção do conhecimento (BNGLEGAL, 2014).

Quadro 4. Relação entre patente, marca e desenho industrial, em milhares, e o PIB, em milhões, de Myanmar no período de 2007 a 2016

\begin{tabular}{|c|c|c|c|c|}
\hline \multicolumn{5}{|c|}{ PI (Doméstica + Externa, Incluindo Regional) e Economia } \\
\hline Ano & Patente & Marca & Desenho & PIB (Constante 2011 US\$) \\
\hline 2007 & & & & 139.67 \\
\hline 2008 & & & & 153.99 \\
\hline 2009 & & & & 170.24 \\
\hline
\end{tabular}




\begin{tabular}{|l|ll|}
2010 & 3.873 & 186.64 \\
2011 & 4.040 & 197.08 \\
2012 & 4.456 & 211.53 \\
2013 & & 229.35 \\
2014 & & 247.68 \\
2015 & & 265.74 \\
2016 & & 283.02 \\
\hline
\end{tabular}

Fonte: WIPO (2016).

Outros exemplos positivos são a Tailândia e Singapura (Quadros 5 e 6), com maior número de patentes e apresentando bons indicadores econômicos, superiores aos da Malásia e Myanmar.

Quadro 5. Relação entre patente, marca e desenho industrial, em milhares, e o PIB, em milhões, da Tailândia no período de 2007 a 2016

\begin{tabular}{|r|r|r|r|r|}
\hline \multicolumn{5}{|c|}{ Pl (Doméstica + Externa, Incluindo Regional) e Economia } \\
\hline Ano & Patente & Marca & Desenho & PIB (Constante 2011 US\$) \\
\hline 2007 & 1.130 & 28.131 & 3.113 & 834.53 \\
2008 & 1.108 & 28.619 & 3.715 & 848.93 \\
2009 & 1.186 & 29.995 & 4.120 & 843.07 \\
2010 & 1.389 & 29.696 & 3.905 & 906.42 \\
2011 & 1.140 & 31.884 & 3.259 & 914.03 \\
2012 & 1.279 & 35.816 & 3.052 & 980.23 \\
2013 & 1.911 & 39.219 & 3.737 & $1,007.02$ \\
2014 & 1.405 & 37.522 & 5.341 & $1,016.23$ \\
2015 & 1.395 & 42.867 & 4.766 & $1,046.12$ \\
2016 & 1.601 & 46.931 & 5.294 & $1,079.90$ \\
\hline
\end{tabular}

Fonte: WIPO (2016).

Interessante observar que, embora Singapura tenha mais número de patentes, o seu PIB é menor que a Tailândia, demonstrando assim, que outros fatores, além das patentes, podem influenciar o PIB de um país.

Quadro 6. Relação entre patente, marca e desenho industrial, em milhares, e o PIB, em milhões, de Singapura no período de 2007 a 2016

\begin{tabular}{|r|r|r|r|r|}
\hline \multicolumn{5}{|c|}{ PI (Doméstica + Externa, Incluindo Regional) e Economia } \\
\hline Ano & Patente & Marca & Desenho & PIB \\
\hline
\end{tabular}




\begin{tabular}{|l|llll|}
2007 & 3.728 & 21.235 & 2.616 & 313.96 \\
2008 & 3.786 & 29.026 & 3.526 & 319.58 \\
2009 & 3.325 & 21.718 & 3.168 & 317.65 \\
2010 & 4.229 & 25.437 & 7.127 & 366.06 \\
2011 & 4.572 & 36.495 & 2.855 & 388.85 \\
2013 & 4.884 & 30.287 & 2.955 & 403.90 \\
2014 & 5.471 & 39.345 & 7.029 & 424.10 \\
2015 & 5.927 & 43.058 & 8.690 & 439.25 \\
2016 & 6.185 & 44.371 & 4.450 & 447.74 \\
\hline
\end{tabular}

Fonte: WIPO (2016).

Analisando-se os dados da Malásia, Myanmar, Tailândia e Singapura, fica evidente a relação positiva entre a proteção do conhecimento e o desenvolvimento econômico.

É importante salientar, porém, que esses indicadores positivos devem ser analisados com cautela, uma vez que o número de patentes de outros países supera as patentes domésticas (Figura 4), o que significa um domínio externo do conhecimento em Singapura.

O ideal, como acontece no Japão, por exemplo, é que o número de patentes domésticas supere o número de patentes externas, ou seja, depositadas por empresas estrangeiras no País. Deste modo, conclui-se que, embora o depósito esteja em Singapura, o conhecimento propriamente dito foi desenvolvido em outro país.

Enquanto o Japão possui 21.006 patentes depositadas na União Europeia, Singapura possui somente 433; permanecendo a desigualdade em outros países, como China (39.207 do Japão x 769 de Singapura), Brasil (Japão 1.829 x Singapura 46) e Alemanha (Japão 6.839 x Singapura 132).

Figura 4. Número de patentes domésticas (resident), estrangeiras (non-resident) e concedidas no exterior (abroad), em milhares, em Singapura, no período de 2007 a 2016. 


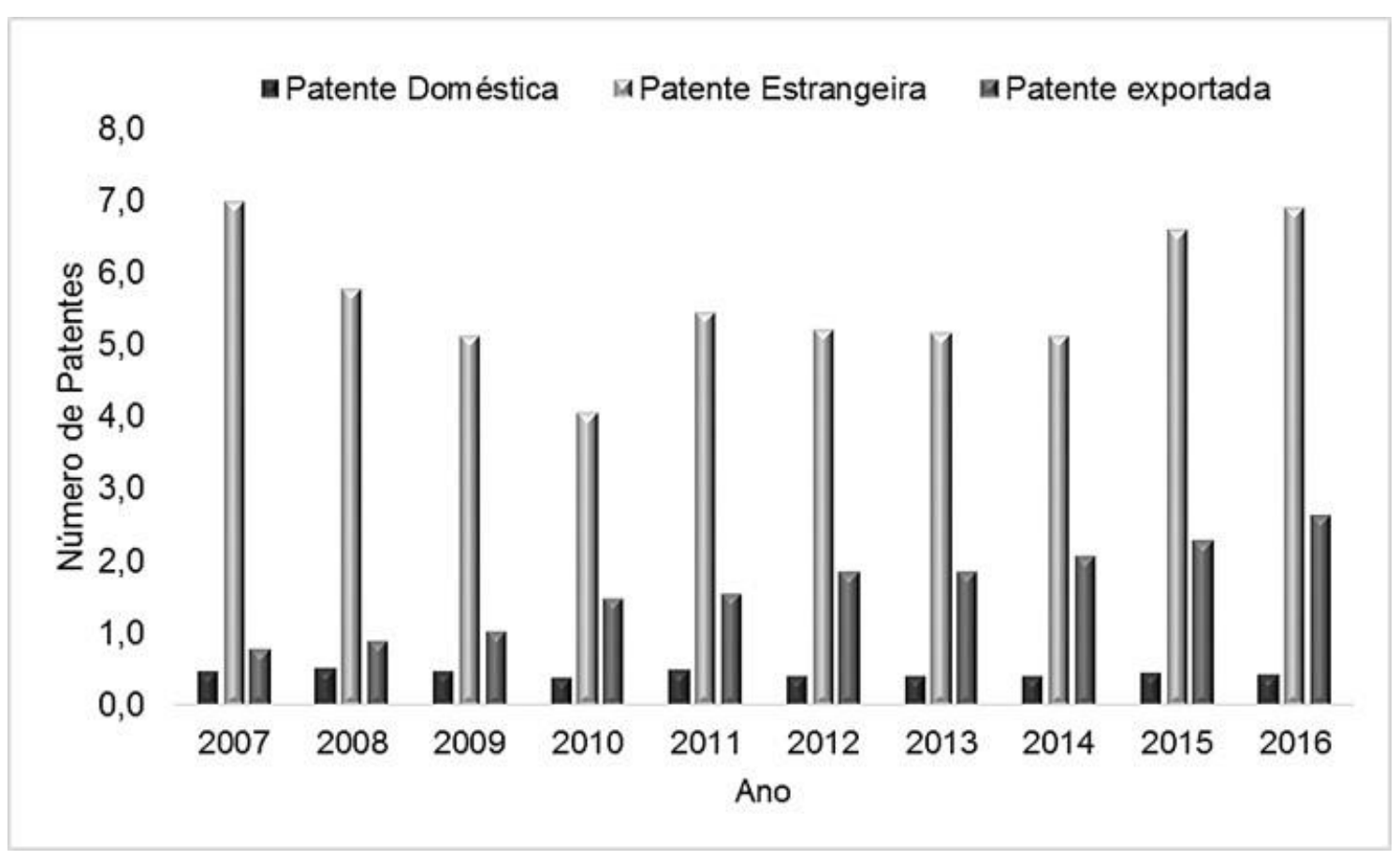

Fonte: Adaptado de WIPO (2018).

Esse argumento é corroborado por DREXL et al. (2009). Segundo eles, um País só alcança o pleno desenvolvimento econômico se a sua trajetória como nação estiver estreitamente ligada ao desenvolvimento de uma estrutura de proteção ao conhecimento doméstico. Notadamente, essa estrutura somente é possível se a Nação compreender que a mola propulsora e geradora de riquezas é a propriedade intelectual sobre a sua riqueza industrial e natural e investir sólidos recursos financeiros para fixação desse conhecimento em território nacional.

Em outros países da Ásia, o desenvolvimento da propriedade intelectual foi influenciado por outros aspectos. Na Tailândia, a lei escrita remonta a 1805, com a Lei dos Três Selos. Embora se trate de um país tradicional, o rei Rama V (1868-1910) deu abertura jurídica aos tribunais locais para aplicarem, em caso de lacuna, os princípios das leis do Reino Unido. Além disso, a codificação do direito civil e comercial foi influenciada pelo Código Civil Francês e Japonês. Devido a essa abertura, não foi difícil a sua adesão aos tratados internacionais contemporâneos, como o Acordo TRIPS (SORG, 2009). 


\subsection{A propriedade intelectual como instrumento industrialização da Índia}

O período abordado compreende o período de 1800 até a sua adesão ao Acordo TRIPS, em 1994, se concentrando na luta da Índia para se libertar da colonização tecnológica da Coroa Britânica e consolidar seu sistema doméstico de proteção do conhecimento.

Segundo GARDE (2009), a partir de 15 de agosto de 1947, data da sua independência da Grã-Bretanha, a Índia trilhou um novo caminho econômico. Levado pelo espírito otimista de um país livre, o primeiro-ministro Jawaharlal Nehru, discursou: "No momento da meianoite, quando o mundo dorme, a Índia despertará para a vida e a liberdade" (GARDE, 2009, p. $55)$.

Entretanto, esse otimismo não conseguiu sobrepor-se a uma realidade nada otimista. Enquanto o país conseguia sua tão sonhada liberdade, a realidade econômica e social era muito diferente. O setor industrial da época era pequeno, contribuindo apenas para um quarto de renda nacional. Além disso, a produtividade agrícola era baixa e a população estava aumentando. Havia necessidade de reforma agrária como base para um plano de desenvolvimento a longo prazo. Entretanto, dentre tantas prioridades a industrialização era a mais urgente (GARDE, 2009).

Naquela época, um grupo de oito industriais indianos se reuniu para desenvolver o que ficou conhecido como o Plano de Bombaim ${ }^{4}$ e coordenar e centralizar o setor privado era fundamental, pois o setor público vinha de um desgaste político desde a fome em Bengala de $1943^{5}$.

A colonização britânica provocou diversos episódios de fome em diversas regiões da Índia, em 1770, 1783, 1866, 1873, 1892, 1897 e, finalmente, o período de 1943-1944, em Bengala, reconhecido historicamente como o período mais devastador de todos (Figura 5).

Os méritos do plano não estavam em seus detalhes, mas sim identificando uma maneira de avançar. O plano de desenvolvimento econômico apoiou o controle estatal sobre setores de interesse comunitário, como energia, infraestrutura e transporte, setores que mais afetavam a

\footnotetext{
4 SANYAL, A. The Bombay Plan: A forgotten document. [online]. Disponível em: 〈https://nzsac.files.wordpress.com/2012/05/bombayplanfornzsac.pdf>. Acesso em: 16 jan. 2018.

5 CHAKRABORTY, R. The Bengal famine. [online]. Disponível em: <https://yourstory.com/2014/08/bengalfamine-genocide/>. Acesso em: 16 jan. 2018.
} 
comunidade em geral. O trabalho foi instrumentalizado via Diretivas da Política Estadual na Constituição Indiana, com a afirmação de que o bem comum é melhor preservado se houver controle dos recursos materiais da comunidade. Foram dois os pressupostos do Plano de Bombaim: primeiro, a existência de um governo nacional no centro, investido de plena liberdade em questões econômicas e, em segundo lugar, a manutenção da unidade econômica da Índia (GARDE, 2009).

À medida que a Índia desenvolveu sua política industrial, o foco foi incentivar as indústrias domésticas, refletindo o sentimento de que o Raj britânico havia desencorajado intencionalmente o crescimento industrial indiano através de distorções das regras tarifárias e comerciais para favorecer as empresas britânicas. Consequentemente, quando a Índia considerou qual modelo econômico empregar, o capitalismo era equiparado a uma forma de colonialismo. A preocupação com a industrialização era o medo de que a riqueza e o poder se concentrassem nas mãos de poucos. Como observou Gandhi: "É uma maquinaria [...] que tem empobrecido a Índia" (GARDE, 2009, p. 56).

Figura 5. Fome em Bengala (1943-1944) reconhecido historicamente como o período mais devastador de todos.

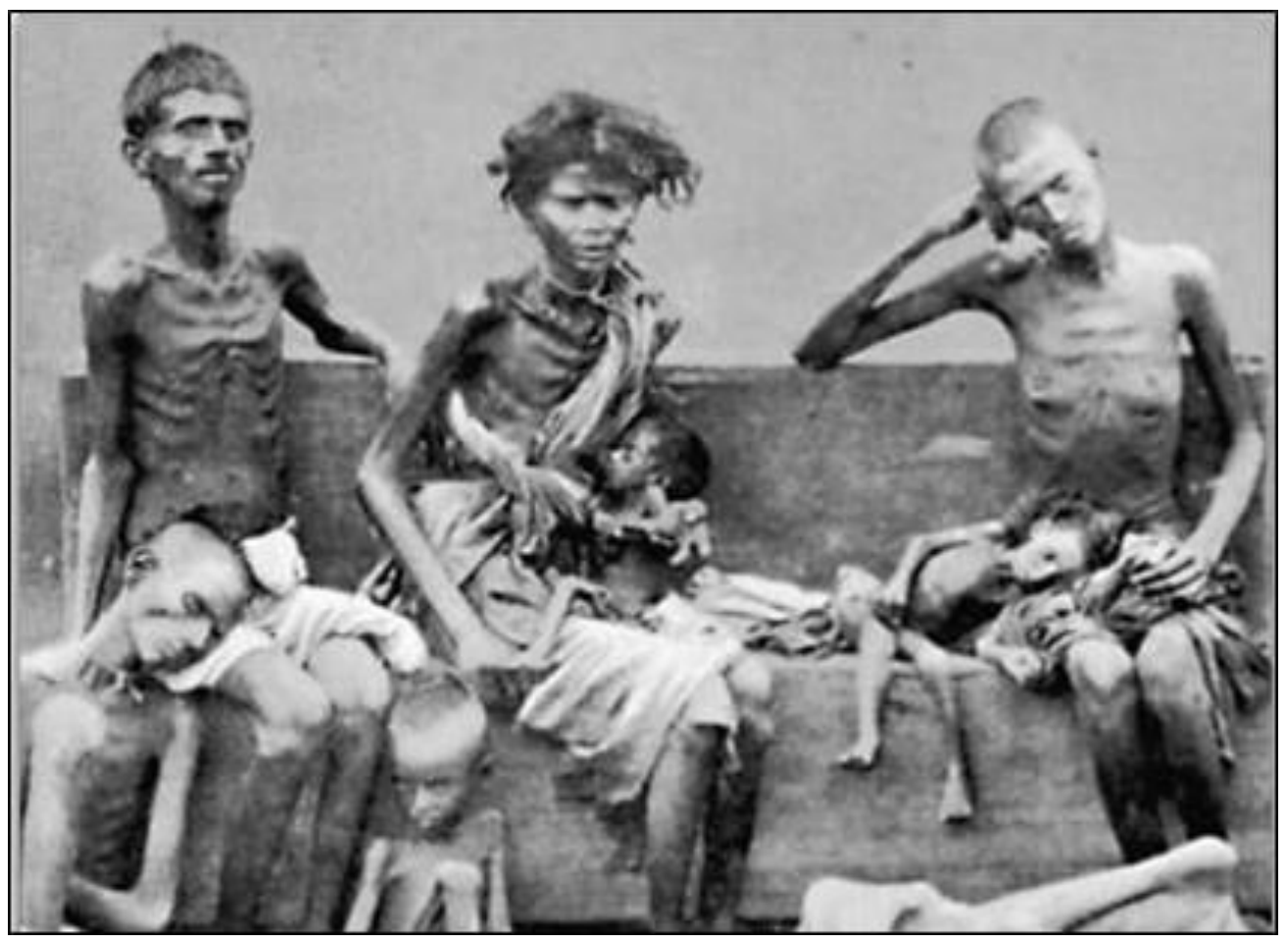

Fonte: Yourstory (2014). 
Um dos principais atores da industrialização da Índia foi Prasanta Chandra Mahalonobis, responsável pela elaboração do Segundo Plano Quinquenal, também conhecido como Modelo de Planejamento de Mahalanobis. Este modelo propôs uma abordagem nacionalista para a industrialização, defendendo a autossuficiência sobre produtos manufaturados estrangeiros (GARDE, 2009).

Entretanto, para Garde (2009), foi a adesão da Índia ao Acordo TRIPS redefiniu o contexto de proteção da propriedade intelectual no país e, de certa forma, reduziu a soberania nacional em relação às leis de patentes. Alcançar o padrão de proteção em nível das convenções internacionais foi muito difícil para os indianos. Entretanto, a Índia ao longo da sua evolução, tem procurado alinhar sua agenda de propriedade intelectual com as de muitos países em desenvolvimento e isso se refletiu no número de patentes (Quadro 7).

Quadro 7. Relação entre patente, marca e desenho industrial, em milhares, e o PIB, em milhões, da Índia no período de 2007 a 2016

\begin{tabular}{|r|r|r|r|r|}
\hline \multicolumn{5}{|c|}{ PI (Doméstica + Externa, Incluindo Regional) e Economia } \\
\hline Ano & Patente & Marca & Desenho Industrial & PIB \\
\hline 2007 & 10.529 & 133.660 & 6.553 & 4.363 .38 \\
2008 & 11.546 & 142.590 & 5.478 & 4.533 .16 \\
2009 & 11.939 & 153.938 & 4.886 & 4.917 .56 \\
2010 & 14.869 & 190.326 & 6.738 & 5.422 .10 \\
2011 & 15.896 & 194.796 & 8.179 & 5.782 .04 \\
2012 & 18.202 & 197.877 & 7.137 & 6.097 .53 \\
2013 & 20.908 & 204.987 & 7.005 & 6.486 .92 \\
2014 & 22.445 & 237.244 & 8.021 & 6.973 .78 \\
2015 & 23.990 & 283.346 & 9.257 & 7.532 .38 \\
2016 & 25.845 & 294.598 & 7.882 & 8.067 .71 \\
\hline
\end{tabular}

Fonte: WIPO (2016).

Na Índia, como também na maioria dos países da Ásia, o número de patentes externas (non-residents) superam o número de patentes domésticas (Figura 6), o que significa um baixo spillover de conhecimento, demonstrando assim que o País ainda está sendo "colonizado tecnologicamente" pelos países desenvolvidos.

Figura 6. Número de patentes domésticas (resident), estrangeiras (non-resident) e concedidas no exterior (abroad), em milhares, na Índia, no período de 2007 a 2016. 


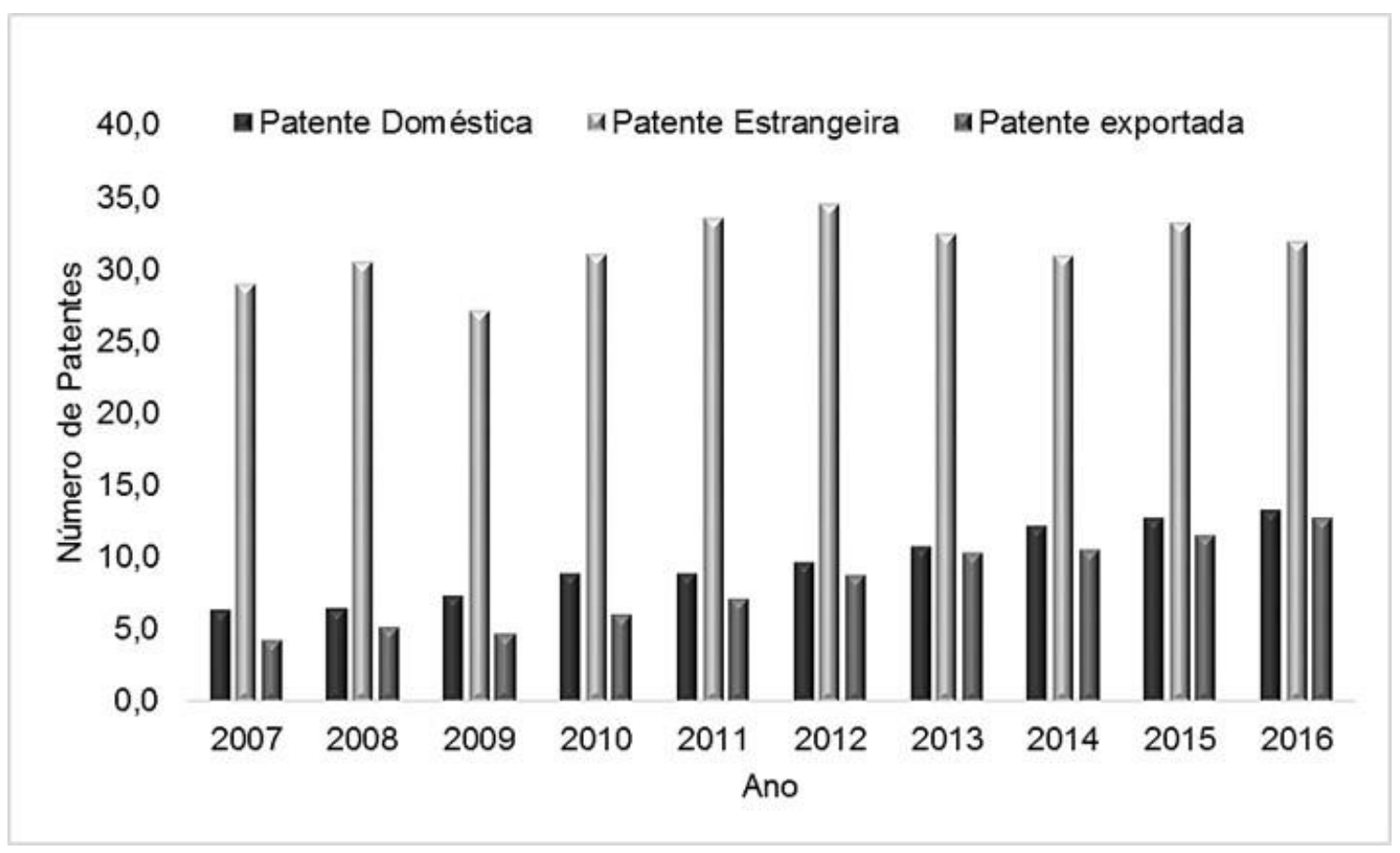

Fonte: Adaptado de WIPO (2018).

\subsection{A China e o desafio dos direitos de propriedade intelectual}

Segundo GANEA e Jin (2009), até 1978, a propriedade intelectual tinha pouquíssimas publicações na China. Mesmo os livros existentes traziam conceitos rudimentares a respeito desse tema em textos antigos que remontavam até os séculos X e XIII. Exemplos desses conceitos incluem a concessão de direitos exclusivos de impressão e publicação, que é semelhante aos privilégios de impressão europeus e um direito exclusivo de usar determinada tecnologia de destilação de sal ou fundição de ferro. No entanto, um sistema de privilégios reais nunca foi desenvolvido, uma vez que a concessão de tais direitos de exploração exclusivos dependia da boa vontade das autoridades locais.

O primeiro contato da China com o conceito ocidental de propriedade intelectual aconteceu no final do século XIX e início do século XXI, mas não teve o mesmo impacto que no seu vizinho Japão, onde as primeiras leis de propriedade intelectual nasceram naturalmente, sem a intervenção do colonizador. Ao contrário, a China se tornou uma pseudo-colônia de potências ocidentais (e do Japão) e nunca teve a chance de desenvolver seu próprio sistema de proteção do conhecimento, nem como avaliar os seus efeitos no desenvolvimento. 
Em vez disso, foi forçada a assinar uma série de tratados comerciais bilaterais que continham cláusulas sobre a proteção de direitos autorais e marcas estrangeiras. Mesmo assim, os chineses reconheceram que a proteção do conhecimento seria um instrumento legal que poderia contribuir para o crescimento do seu país. O último imperador promoveu a ideia de proteção de patentes e em 1898, decretou um conjunto de regras semelhantes a patentes, o Regulamento sobre recompensas para a promoção da tecnologia. No entanto, o documento não chegou a ser colocado em prática devido a uma intervenção da poderosa Imperatriz Cixi (Figura 7) (GANEA e JIN, 2009).

Figura 7. A Imperatriz viúva Tseu-Hi ou Cixi, poderosa e carismática mulher que governou a China da Dinastia Qing durante 47 anos, de 1861 até à sua morte em 1908.

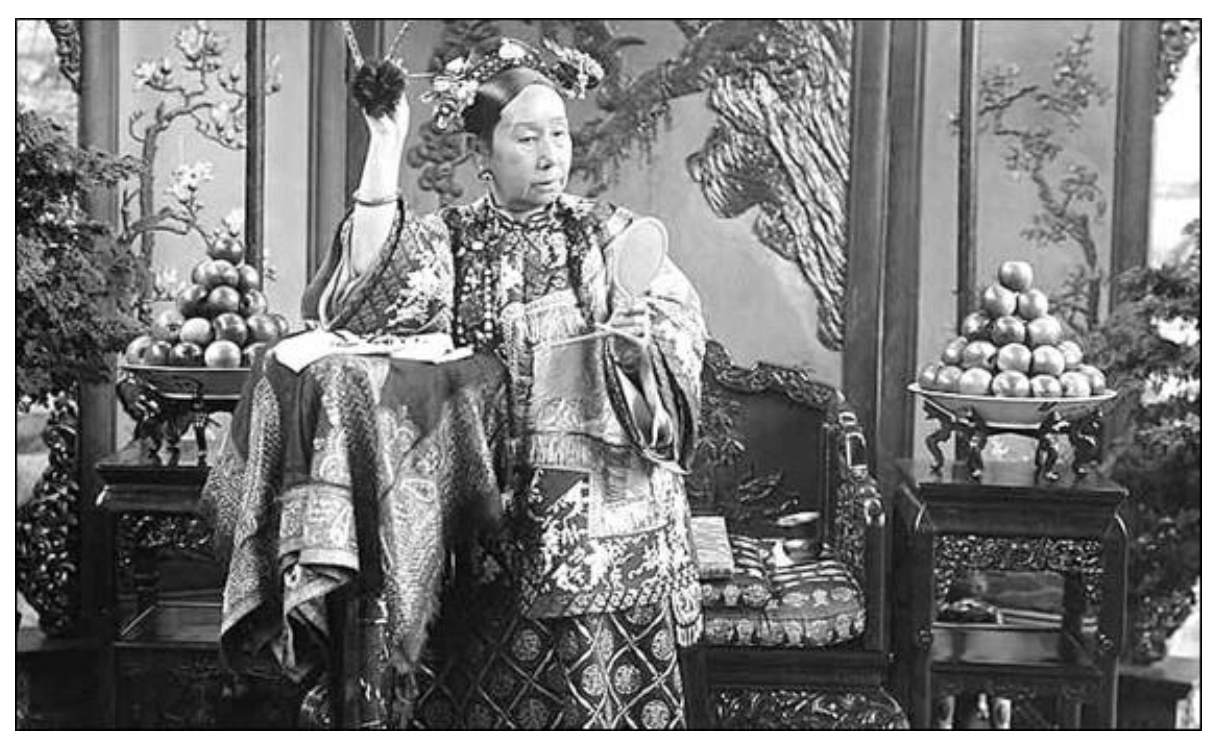

Fonte: CHANG (2014).

A era republicana caótica que seguiu a queda do Império também criou um ambiente difícil para a adoção de novas medidas legais. Esta dificuldade foi ainda agravada por Mao Zedong, que denunciou propriedades de todos os tipos. Nos primeiros anos do governo comunista, depois de 1949, o governo tentou estabelecer os sistemas de remuneração do autor e um sistema dual de certificados de inventor para propriedade de patentes, mas os sistemas não vingaram (GANEA e JIN, 2009).

Foi em 1978, durante a Terceira Sessão Plenária do $11^{\circ}$ Comitê Central do Partido Comunista da China, que surgiu um movimento liderado por Deng Xiaoping, para reforma econômica do sistema. Esse movimento queria a abertura ao capital estrangeiro, visto que até 
então não havia proteção legal para que estrangeiros investissem. Então, a partir do início da década de 1980, a China promulgou leis básicas de direitos de propriedade intelectual, compostas de: Lei das marcas comerciais, Lei de patentes (incluindo a proteção de modelos de utilidade), a Lei de direitos autorais e a Lei da concorrência desleal (GANEA e JIN, 2009).

A legislação de propriedade intelectual seguiu as orientações dos tratados multilaterais. O estabelecimento de um ambiente jurídico estável representou um enorme desafio, porque no início da política de abertura e reforma, a China não possuía nem leis e nem estruturas administrativas de proteção da propriedade intelectual. Além disso, precisava aderir aos padrões internacionais de proteção baseados em negociações unilaterais (GANEA e JIN, 2009).

O primeiro passo para a abertura ao capital estrangeiro se deu em 07 de julho de 1979, quando a China firmou dois acordos bilaterais com os Estados Unidos, um na área da física para produção de energia e outro na área comercial. Neles, a China se comprometeu a proteger as obras dos EUA em bases bilaterais e a se filiar à Convenção Universal sobre Direito de Autor (UCC) (GANEA e JIN, 2009).

A China aderiu à Convenção de Paris e à Convenção de Berna em 10 de julho de 1992. Em 30 de julho de 1992, se juntou à UCC e, em 5 de janeiro de 1993, aderiu à Convenção de Genebra. Todas essas adesões foram para melhorar as relações com os EUA, cada vez mais preocupado em combater a pirataria que batia recordes de pirataria. A China ainda aderiu à WIPO em 1980. De todos os principais acordos internacionais, a China, só não aderiu à Convenção de Roma, mas, como é membro da OMC, ela necessariamente tem que cumprir os acordos de proteção dos direitos dos artistas intérpretes ou executantes, dos produtores de fonogramas e dos organismos de radiodifusão abarcados pela Convenção de Roma (GANEA e JIN, 2009).

Todo esse esforço em alinhar-se às normas internacionais foi sendo consolidado aos poucos; porém, o que realmente tornou o País uma potência foi a sua vocação para o patenteamento doméstico (Figura 8).

Na China o número de patentes domésticas supera, em muito, o número de patentes externas, demonstrando assim, a sua capacidade de produção e fixação do conhecimento em seu território. 
Outro dado igualmente interessante é a sua capacidade de transbordamento de tecnologia (Quadro 8). Na China, o transbordamento de tecnologia vem ocorrendo desde o início dos anos 2000 e seu abroad vem crescendo significativamente. Em 2008 eram 9.689 patentes no exterior e esse número foi crescendo, até chegar a 60.310 em 2017 (Quadro 8).

Figura 8. Número de patentes domésticas (resident), estrangeiras (non-resident) e concedidas no exterior (abroad), em milhares, na China, no período de 2007 a 2016.

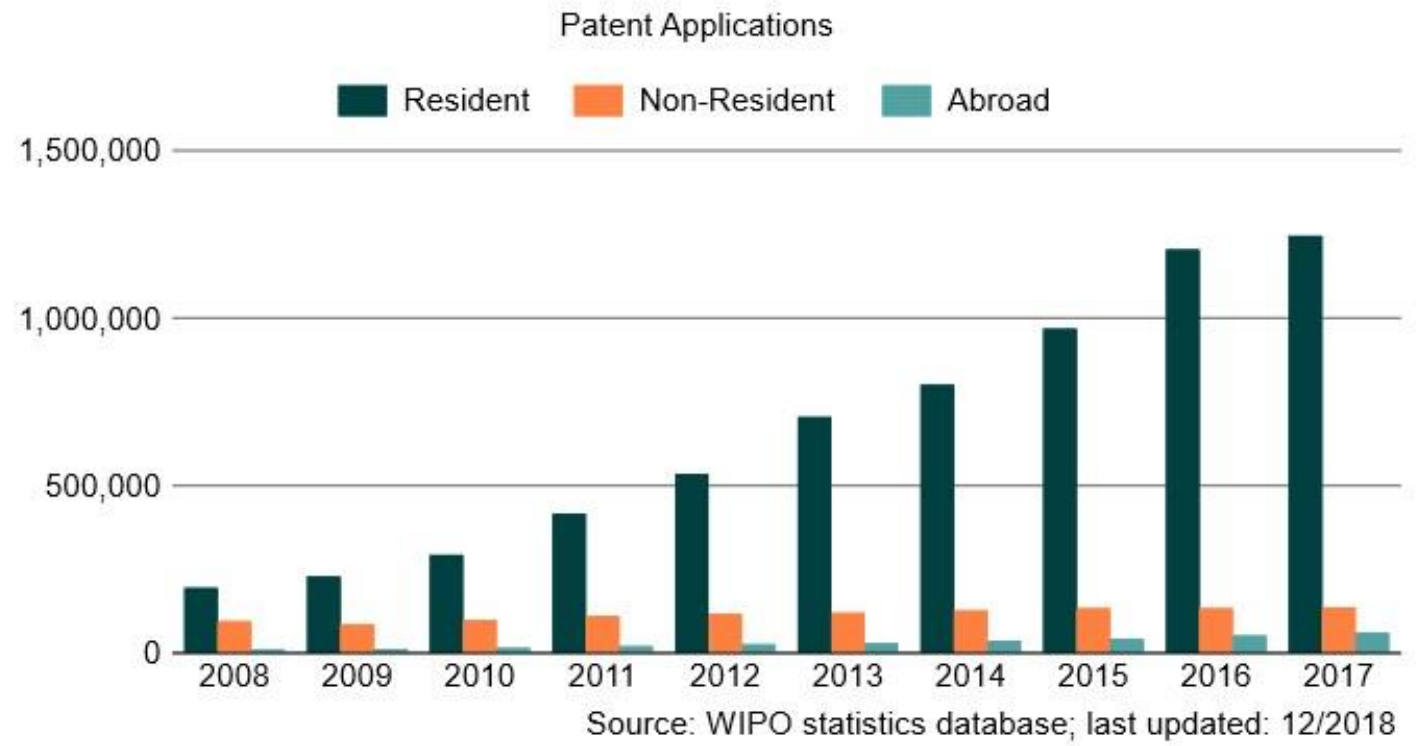

Fonte: Adaptado de WIPO (2018).

A superação do número de patentes domésticas em relação ao número de patentes estrangeiras demonstra sua capacidade produtiva da China. Entretanto, o baixo desempenho na exportação de patentes evidencia que a estratégia do País ainda é copiar o que outros países inventaram, o que não é mais aceito em âmbito internacional.

Quadro 8. Aplicações das patentes domésticas (resident), externas (non-resident) e, exportadas (abroad) da China, em milhares, no período de 2007 a 2016

\begin{tabular}{|l|r|r|r|}
\hline Ano & Doméstica & Estrangeira & Externa \\
\cline { 1 - 1 } 2008 & 194.579 & 95.259 & 9.689 \\
2009 & 229.096 & 85.508 & 12.338 \\
2010 & 293.066 & 98.111 & 15.260 \\
2011 & 415.829 & 110.583 & 20.341 \\
2012 & 535.313 & 117.464 & 26.095 \\
2013 & 704.936 & 120.200 & 29.160 \\
2014 & 801.135 & 127.042 & 36.682
\end{tabular}




\begin{tabular}{|c|c|c|c|}
\hline 2015 & 968.252 & 133.612 & 42.363 \\
\hline 2016 & 1.204 .981 & 133.522 & 52.428 \\
\hline 2017 & 1.245 .709 & 135.885 & 60.310 \\
\hline
\end{tabular}

Fonte: WIPO (2016).

No país, a hierarquia jurídica é formada pelos Tribunais Populares Municipais, em nível de cidade, seguido pelos Tribunais Populares Intermediários, em nível distrital e, Tribunais Populares Superiores, em nível provincial. A suprema autoridade judicial é o Supremo Tribunal Popular, que também tem alguma autoridade legislativa. Muitos tribunais foram equipados com câmaras especializadas em propriedade intelectual, mas a experiência acumulada nessas câmaras varia conforme a região. A maioria dos casos envolvendo direitos de propriedade intelectual é apresentada perante os tribunais populares em Pequim e Xangai, por terem acumulado maior experiência nessa área (GANEA e JIN, 2009).

O Tribunal Popular Intermediário de Pequim n. 1 tem jurisdição de primeira instância em casos de revisão das decisões do Escritório de Patentes. Além de decidir os casos, esses tribunais populares superiores estão envolvidos na publicação de coleções de casos por eles julgados. O Tribunal Popular Superior também emitiu algumas regras de interpretação detalhadas sobre como lidar com certos aspectos de violação de patentes. Essas regras, no entanto, só podem servir como material de referência. Somente o Supremo Tribunal Popular está autorizado a emitir disposições de interpretação vinculativa (algo como as jurisprudências no Brasil) e algumas de suas decisões recentes. As emendas de 2000-2002 à Lei de Patentes, à Lei de Marcas e à Lei de Direitos Autorais implicaram uma série de esclarecimentos para melhorar a aplicação das leis (GANEA e JIN, 2009).

A estrutura jurídica para proteção dos direitos de propriedade intelectual é relativamente recente. Esse fato exige um caminho duplo para a solução das controvérsias envolvendo esses direitos: via tribunais ou, via administração. O sistema judicial é continuamente criticado, apesar das reformas recentes, pelos procedimentos dispendiosos e demorados, decisões imprevisíveis e remédios jurídicos insuficientes, especialmente na área de danos. Os procedimentos administrativos são menos onerosos e mais rápidos, mas produzem resultados menos confiáveis. No decurso da onda de alteração da propriedade intelectual entre 2000 e 2001, as competências quase judiciais das administrações foram consideravelmente reduzidas (GANEA e JIN, 2009). 
Segundo GASSMANN et al. (2012), embora a China tenha avançado na consolidação de normas e estruturas jurídicas para a proteção dos direitos de propriedade intelectual, o país ainda enfrenta desafios gigantescos nessa área. O fenômeno das contrafações originárias aumentou constantemente nas últimas duas décadas. Além disso, nos últimos 10 anos a escala de roubo de propriedade intelectual aumentou exponencialmente em termos de sua sofisticação, seu volume, a gama de bens e os países afetados. A China está conseguindo sair na liderança de países produtores e comerciantes de bens falsificados.

Nos anos 2000, a China consolidou a fabricação de bens legítimos em 65 a $70 \%$ da sua produção total. Foi um avanço, mas não o suficiente, devido a grandiosidade da sua produção industrial. Para se ter uma ideia, em 2009, as alfândegas da União Europeia apreenderam mais de 118 milhões de produtos falsificados e pirateados, levando ao pressuposto de que a produção de falsificações em grandes quantidades provavelmente continuará neste século (GASSMANN et al., 2012).

Embora os produtos têxteis sejam o produto de contrafacção mais interceptado, as indústrias de fabricação e bens industriais constituem uma ameaça crescente em relação aos produtos pirateados. De acordo com uma pesquisa de 2007 da Federação Alemã de Engenharia, $67 \%$ das empresas entrevistadas alegaram ter sofrido pirataria de seus produtos. Em $60 \%$ dos casos, máquinas inteiras foram alvo de imitação, enquanto que em $42 \%$ dos casos, as peças de reposição foram copiadas (GASSMANN et al., 2012).

Em escala global, os números impressionam. Segundo Gassmann et al. (2012), 3/4 de todas as imitações do mundo, são da China. O mais grave disso tudo é que as imitações vão além dos produtos e das suas peças de reposição. Recentemente, a China falsificou um grupo inteiro de lojas falsas Apple (Figura 9).

Figura 9. Existem mais de 30 lojas da Apple na cidade de Shenzhen (sul da China), das quais apenas uma é original. As 29 restantes são falsas. 


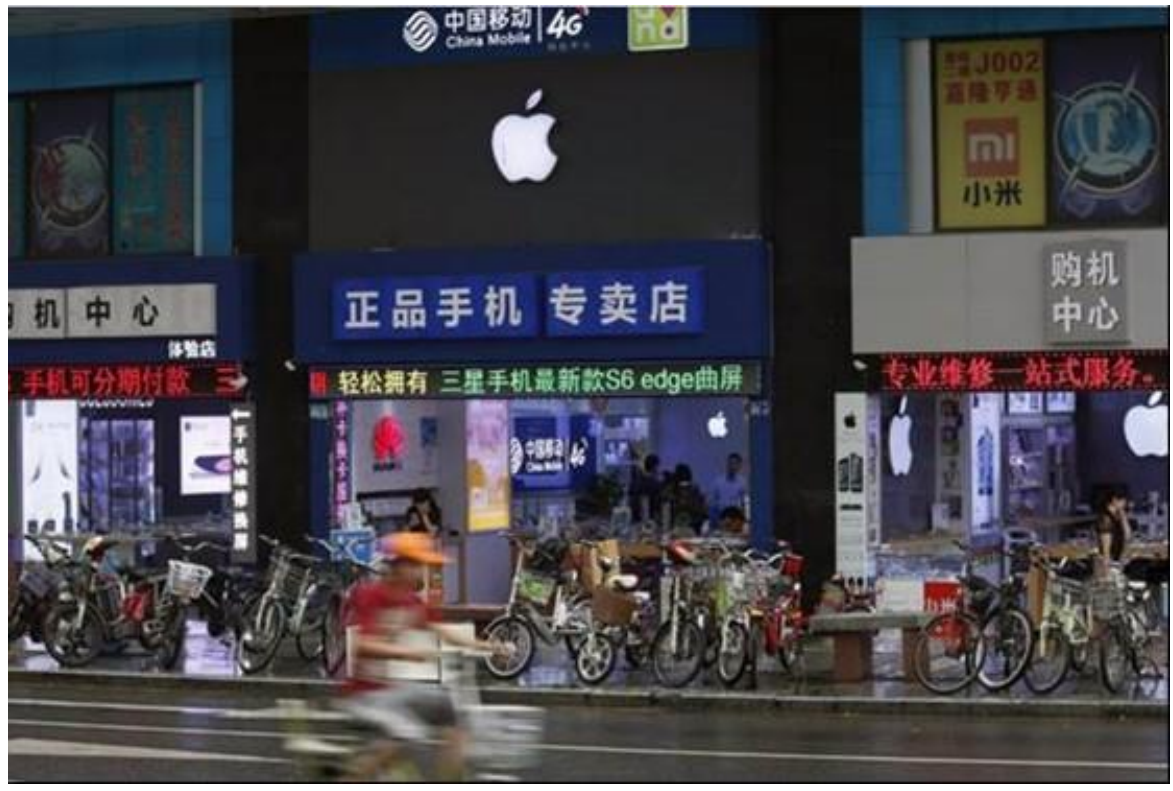

Fonte: Business Insider (2018).

Essas lojas não só vendiam bens falsos; eles imitavam toda a aparência das lojas originais, com seus layouts, assim como as roupas dos funcionários e os cartazes promocionais nas paredes. O mesmo aconteceu com a IKEA, loja de departamentos para o lar. Em Kunming, no sudoeste da China, existe uma loja falsa. A falsificação não é percebida facilmente e todas as características, nos mínimos detalhes foram copiadas: o layout, os lápis pequenos, os produtos e até mesmo os sacos de compras amarelos. A loja é chamada de Shi Yi Jiaju, mas, o nome da IKEA na China é Yi Jia-Jiaju. É preciso muita atenção para perceber a diferença (GASSMANN et al., 2012).

A partir da sua adesão à OMC, em 2001, a China desencadeou um processo de nivelamento das suas leis de propriedade intelectual para cumprir as obrigações do Acordo TRIPS. Entretanto, as empresas estrangeiras ainda enfrentam riscos relacionados aos seus direitos de propriedade intelectual ao fabricar e comercializar seus produtos em território chinês, principalmente, devido à falta de transparência e fiscalização para garantir os direitos de propriedade intelectual no País (GASSMANN et al., 2012).

Para SHI (2008), essa transição de uma terra praticamente sem lei de proteção à propriedade intelectual, para um nivelamento em relação aos acordos multilaterais globais, não poderia acontecer sem alguma tensão nas negociações. $\mathrm{Na} 12^{\circ}$ reunião anual sobre as Perspectivas Econômicas Globais (The World Bank. Global Economic Prospects and the 
Developing Countries), o Banco Mundial debate com aprofundamento necessário a arquitetura dos acordos comerciais globais, bem como o seu impacto nos países em desenvolvimento na próxima década. Ele termina com o seguinte comentário: O Acordo TRIPS 2 aumentou significativamente os requisitos para proteger a propriedade intelectual que incumbe as nações que desejam fazer parte do sistema de comércio global (SHI, 2008).

A China, assim como os demais países em desenvolvimento, temendo a marginalização de uma economia global em rápida mudança, fizeram uma mudança dramática em direção à sua política externa e mostraram entusiasmos imprevisíveis na atualização de seus sistemas legais nacionais. Como resultado, após o estabelecimento do Acordo TRIPS, a proteção internacional de propriedade intelectual foi gerenciada em um processo acelerado de padronização em todo o mundo, com países em desenvolvimento sendo participantes ativos (SHI, 2008).

O transplante do direito da propriedade intelectual através da OMC representou um modelo único de reforma legal imposta pelas nações industrializadas no contexto da globalização em época de política de liberação econômica. Foi dada ênfase substancial ao conceito de transplantes legais no contexto do direito comparado. Embora a divergência entre os otimistas e os céticos da teoria permaneça, mais estudiosos tendem a acreditar na transferibilidade de leis estrangeiras, desde que seja garantido um processo de adequação em um ambiente socioeconômico diferente (SHI, 2008).

Uma das grandes dificuldades nessa transposição jurídica está no fato da propriedade intelectual ter sido, tradicionalmente, considerada como um conceito cultural até 1994, quando, por força do Acordo TRIPS, foi transformada em questão comercial. Deste modo, as nações são obrigadas a aceitar a visão prevalecente sobre o papel adequado dos direitos de propriedade intelectual, como forma de inclusão nas negociações mundiais, lideradas pela OMC (SHI, 2008).

A posição da China frente ao Acordo TRIPS é respeitada, devido a sua importância como nação milenar, e pelo seu potencial de mercado e investimentos. Sob esse argumento a OMC não aplica a totalidade das sanções do Acordo TRIPS, como por exemplo a sua exclusão da OMC, o que resultaria no fechamento de um gigantesco mercado que os países não querem abrir mão. Afinal, ela abriga cerca de $20 \%$ da população mundial disposta ao trabalho e ao 
consumo. Em novembro de 2001, após quinze anos de negociações difíceis, a China aderiu a OMC e permitiu envolver-se plenamente na comunidade global de comércio e está agora em uma posição para aumentar sua credibilidade como gigante mundial do comércio mundial. Em 2001, tornou-se o segundo maior importador do mundo, compartilhando $9,41 \%$ das importações totais e ganhou uma posição de liderança em vários mercados globais. É líder mundial no setor têxtil e produz $70 \%$ de todos os telefones celulares e câmeras digitais e, 50\% de todos os computadores (SHI, 2008).

Nos últimos anos, a China vem se consolidando, ainda, como o maior mercado mundial de sistemas de refrigeração e ar condicionado, o segundo maior mercado de energia e o terceiro, de eletrônicos. No entanto, embora o país tenha saído publicamente e inequivocamente a favor de uma nova rodada de negociações comerciais multilaterais, as expectativas de que assumirão um papel positivo nas questões decorrentes do TRIPS ainda não foram realizadas, e a proteção dos direitos de propriedade intelectual na China parece estar constantemente em controvérsia (SHI, 2008).

É importante o debate, pois as nações desenvolvidas sabem que a eficácia de um regime de proteção dos direitos de propriedade intelectual depende, não apenas das estruturas jurídicas, mas também de superestrutura política, da diversidade cultural, da infraestrutura econômica e da capacidade técnica do país. Embora o cumprimento formal das obrigações do TRIPS tenha sido razoavelmente bom, os seus desdobramentos práticos foram fracos (SHI, 2008).

Um Relatório da Seção 301 dos Estados Unidos (Office of the United States trade representative. Special 301) mostra que a lei de direitos autorais chinesa, por exemplo, está em conformidade com os requisitos do Acordo TRIPS, tanto em termos de alcance quanto de período; entretanto, a pirataria de direitos autorais continua a ser um grande problema, que está piorando em áreas como gravações de som, o que vem incomodando bastante os países da OMC. Em um exemplo do descumprimento das normas de proteção ao conhecimento e do lucro envolvido nesse comércio ilegal, o autor cita o Relatório da International Intellectual Property Alliance (IIPA), sobre lucro do comércio de vídeos pirateados e gravações clandestinas: cerca de US\$ 202 milhões, em 2004, US\$ 204 milhões, em 2005, e, US\$ 206 milhões, em 2006 (SHI, 2008). 
Portanto, a solução para o problema vai muito além de questões relacionadas aos acordos multilaterais. Elas envolvem negociações no âmbito da política econômica e isso deverá perdurar por alguns anos.

Comparando a China com a Coreia do Sul, o quadro é bem diferente. Segundo PARK (2012), o marco legal da propriedade intelectual na Coreia do Sul remonta a 1908, ao final da dinastia Chosun, com a promulgação de um decreto regulamentando patentes, desenhos industriais, marcas comerciais e direitos autorais. Em 1910, a Coreia foi anexa ao Japão, porém, esses Decretos Reais, prevalecendo a legislação japonesa, assim permanecendo até 1945, com o fim da colonização japonesa.

Em âmbito internacional, a Coreia do Sul aderiu à WIPO em 1979, marco inicial como País signatário de acordos multilaterais, desencadeando, consequentemente, a sua adesão à Convenção de Paris, em 1980, cujo resultado imediato foi o compromisso de estender o tratamento nacional aos estrangeiros, em nível de proteção dos direitos de propriedade intelectual, conforme preceitua essa Convenção. A consequência imediata foi o aumento do número de patentes estrangeiras em território coreano, como podemos constatar no quadro 9 (PARK, 2012).

Entretanto, mesmo com a adesão ao Acordo TRIPS em 1993, a Coreia do Sul conseguiu implementar uma estratégia de desenvolvimento pautada na consolidação do conhecimento doméstico, conforme demonstra o quadro 9.

Quadro 9. Aplicações das patentes domésticas (resident), externas (non-resident) e, exportadas (abroad), em milhares, da Coreia do Sul no período de 2007 a 2016

\begin{tabular}{|l|r|r|r|}
\hline Ano & Doméstica & Estrangeira & Externa \\
\hline 2008 & 127.114 & 43.518 & 46.382 \\
2009 & 127.316 & 36.207 & 42.917 \\
2010 & 131.805 & 38.296 & 46.849 \\
2011 & 138.034 & 40.890 & 49.713 \\
2012 & 148.136 & 40.779 & 55.700 \\
2013 & 159.978 & 44.611 & 63.549 \\
2014 & 164.073 & 46.219 & 66.480 \\
2015 & 167.275 & 46.419 & 70.910 \\
2016 & 163.424 & 45.406 & 70.371 \\
2017 & 159.084 & 45.691 & 67.484 \\
\hline
\end{tabular}

Fonte: WIPO (2018). 
Analisando os indicadores da Coreia, percebe-se que essa cultura de proteção, paulatinamente, foi ganhando força, e as patentes domésticas estão aos poucos vencendo as patentes estrangeiras (Figura 10).

Essa estratégia resultou em uma indústria forte e coesa. Os sacrifícios iniciais de adequação a um objetivo nacionalista alavancaram a Coreia a um patamar de desenvolvimento tecnológico de projeção internacional. Cita-se como exemplo a força do setor de telecomunicações coreano, resultado de uma política de estruturação de linhas de fibra ótica que ligou todo o país. Esse setor foi de capital importância para a indústria de Tecnologia da Informação e para os setores que têm a Internet como elemento essencial para o seu desenvolvimento (KIM, 2005)

Figura 10. Número de patentes domésticas (resident), estrangeiras (non-resident) e concedidas no exterior (abroad), em milhares, na Coreia do Sul, no período de 2007 a 2016.

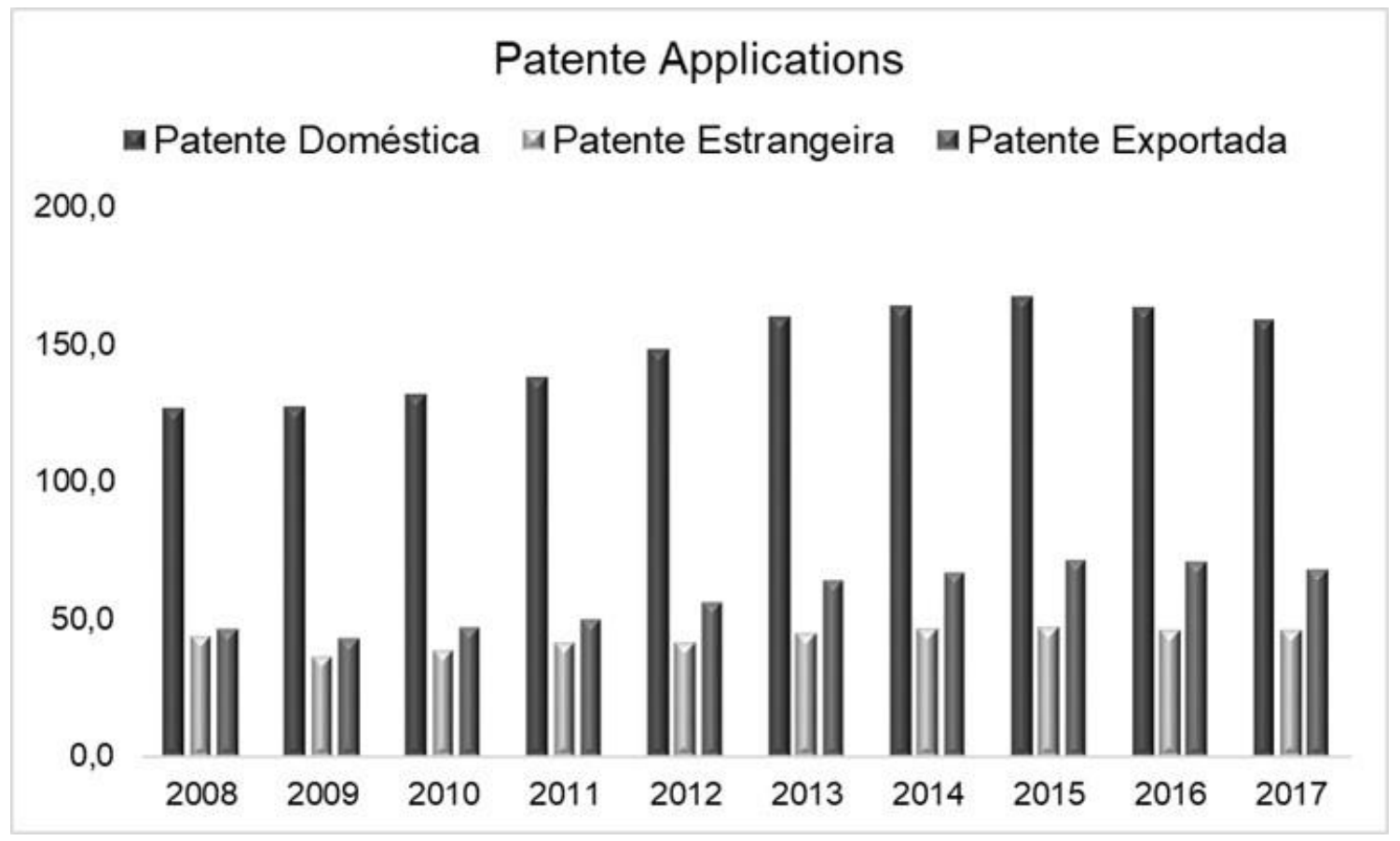

Fonte: Adaptado de WIPO (2018).

Os resultados desse esforço foram os indicadores econômicos. O PIB de US\$ 80,00 por ano, nos anos 1960, equiparava-se ao de países pobres como Gana e Sudão. Passadas décadas e um crescimento em torno de $9 \%$ ao ano, a Coreia ostentou em 2017 um PIB de US\$ 1.849,71, tornando-se assim um destaque mundial (WIPO, 2018). 
Para dar suporte jurídico à proteção dos direitos de propriedade intelectual, o governo coreano instituiu, em 1994, o Tribunal de Patentes especializado em direitos de propriedade intelectual, cuja competência é dirimir conflitos nessa área. O Tribunal conta com doze juízes experientes na área e que são nomeados pelo Supremo Tribunal da Coreia (PARK, 2012).

Deste modo, os conflitos que não forem solucionados em âmbito administrativo pelo Governo coreano serão resolvidos pelo Tribunal de Patentes, garantindo assim a segurança jurídica aos empreendedores do setor privado.

\section{CONSIDERAÇÕES FINAIS}

Na Ásia houve uma valorização da propriedade intelectual, estreitamente relacionada à propriedade privada, ou seja, na medida em que os asiáticos se preocupavam em consolidar seu parque industrial, paralelamente, eles também foram estruturando seu sistema de proteção de conhecimento com robusta legislação nas áreas de patentes de invenção, patentes de design e modelos de utilidade; registro de direitos atorais; marca comercial; e concorrência desleal.

Em grande parte, essa sofisticação legislativa, foi pressionada por organismos internacionais como a OMC e a WIPO, pois foi a partir de 1995, com a adesão à WIPO e, 1998, com a adesão à Convenção de Paris, que o Camboja iniciou o processo de consolidação da sua legislação de proteção do conhecimento. Isso fica evidente pelo fato da lei de patentes do Camboja ter sido promulgada em 2003, ou seja, logo em seguida à adesão aos referidos acordos globais.

Entretanto, nem todos os países asiáticos seguiram essa tendência de alinhamento à legislação internacional, como é o caso da Malásia, Camboja, Laos. A Malásia ainda é um dos maiores exportadores mundiais de software pirateado e fica evidente que ocorreu investimentos na infraestrutura de produção; porém, a preocupação em proteger os direitos de propriedade intelectual e direitos de autor não foi prioridade neste país. 
$\mathrm{Na}$ Tailândia, os principais litígios envolvem direitos de propriedade intelectual e violação de direitos autorais e marcas. É um fato curioso, pois o Sistema Legal de proteção ao conhecimento remonta de 1805, com a promulgação da Lei dos Três Selos. Posteriormente, graças à abertura política do Rei Rama V (1868-1910), o poder judiciário foi se adequando ao sistema jurídico do Reino Unido, o que facilitou sua adesão ao Acordo TRIPS, em 1992. Certamente, na Tailândia, a preocupação é com a promulgação das leis; porém, o seu efetivo cumprimento ainda é um desafio para esse país.

Por outro lado, países como Singapura, Tailândia, China, Índia e Coreia do Sul, têm avançado sobremaneira em direção à consolidação de um sofisticado Sistema de Proteção do Conhecimento e isso teve reflexos no crescimento do PIB.

Na Índia, os desafios vão além da proteção do conhecimento. Lá, os desafios são sociais, herdados do processo de colonização tecnológica dos britânicos nos anos 1800. Os privilégios eram exclusivos da Coroa Britânica e foi somente em 1948 que a situação começou a mudar, graças à sua libertação da Coroa Britânica. Nesse período, o novo governo iniciou um sofrível processo de consolidação de proteção do conhecimento, no qual a criação do Comitê de Inquérito às Patentes foi o primeiro passo. Graças à atuação desse Comitê, a Índia reconheceu a necessidade de estimular a invenção com vistas a conseguir a libertação econômica do País. Nos anos 1970, criou a sua Lei de Patentes, reconhecendo a proteção de processos e produtos, inclusive de alimentos e remédios. Em 1997, também aderiu ao Acordo TRIPS e vem envidando esforços para a devida adequação aos mecanismos de proteção internacional de proteção do conhecimento.

Sem dúvida nenhuma, o maior desafio do continente asiático é a China. Até os anos 1970, as referências de propriedade intelectual eram baseadas em livros dos séculos X e XIII. Foi somente a partir do final do século XIX e início do século XXI, com a abertura da economia ao universo capitalista. A partir de então, na década de 1980, a China promulgou leis básicas de direitos de propriedade intelectual, compostas de: Lei das Marcas Comerciais, Lei de Patentes (incluindo a proteção de modelos de utilidade), Lei de Direitos Autorais e a Lei da Concorrência Desleal. A legislação de propriedade intelectual seguiu as orientações dos tratados multilaterais, WIPO, em 1980, Convenção de Paris e Convenção de Berna, em 1992. Embora exista uma hierarquia jurídica formada por Tribunais Populares Municipais, em nível de cidade, seguido pelos Tribunais Populares Intermediários, em nível distrital e, Tribunais 
Populares Superiores, em nível provincial, a garantia do cumprimento das leis ainda é um desafio para uma economia que detêm $20 \%$ do mercado consumidor do mundo, o que vai além de acordos multilaterais, avançando para o campo de uma política econômica globalizada.

Ao avaliar-se o processo de consolidação de proteção do conhecimento nos países estudados na Ásia (Camboja, China, Índia, Indonésia, Japão, Malásia, Myanmar e Coreia do Sul), pode-se afirmar que o que proporcionou o desenvolvimento econômico dos países foi o número de patentes domésticas, identificando que aqueles países que conseguiram aumentar o número de patentes até que apresentaram resultados significativos, tais como Singapura e Tailândia. Porém, os resultados que consolidaram o pleno desenvolvimento somente foram alcançados quando o número de patentes domésticas superou o número de externas, como foi o caso da China e da Coreia do Sul. Na Coreia, além de produzir conhecimento, ainda houve um transbordamento de tecnologia, que resultou em um elevado número de exportação de conhecimento.

\section{REFERÊNCIAS BIBLIOGRÁFICAS}

BNGLEGAL. Patent Law in Cambodia. Cambodia: BNGLEGAL, 2012. [online]. Disponível em: <http://bnglegal.com/>. Acesso em: 15 jun. 2018.

BNGLEGAL. Doing Business in Myanmar. Cambodia: BNGLEGAL, 2014. [online]. Disponível em: <http://bnglegal.com/wp-content/uploads/2014/06/BNG-Doing-Business-inMyanmar-Guide-2014.pdf>. Acesso em: 15 jun. 2018.

BUSINESS INSIDER. What It's Actually Like Inside One of China's Fake Apple Stores. New York, 2018. [online]. Disponível em: <http://www.businessinsider.com/inside-fake-chineseapple-store-shenzen-kunming-2015-9>. Acesso em: 18 jan. 2018.

CHANG, J. A Imperatriz de Ferro. Rio de Janeiro: Saraiva, 2014. 552p.

CLARK, M.; OXMAN, A. Cochrane Reviewers Handbook. Oxford: The Cochrane Library, 2001. 672p.

DREXL, J.; HILTY, R. M.; SCHÖN W.; STRAUS, J. Property Intellectual in Asia: Law, Economics, History and Politics. 1ed. Stanfort: Springer, 2009. 376p.

GANEA, P. Camboja. In: DREXL, J.; HILTY, R. M.; SCHÖN W.; STRAUS, J. Property Intellectual in Asia: Law, Economics, History and Politics. 1ed. Stanfort: Springer, 2009a. p. $1-15$. 
GANEA, P.; JIN, H. China. In: DREXL, J.; HILTY, R. M.; SCHÖN, W.; STRAUS, J. Property Intellectual in Asia: Law, Economics, History and Politics. 1ed. Stanfort: Springer, 2009. p. 1754.

GARDE, T. Índia. In: DREXL, J.; HILTY, R.M.; SCHÖN W.; STRAUS, J. Property Intellectual in Asia: Law, Economics, History and Politics. 1ed. Stanfort: Springer, 2009. p. 5586.

GASSMANN, O.; BECKENBAUER, A.; FRIESIKE, S. Profiting from Innovation in China. New York: Springer, 2012. 130p.

GOOGLE MAPS. Mountain View. 2018. [online]. Disponível em: <https://www.google.com.br/maps/place/Vienciana,+Laos/@ 15.6835839,100.7769784,18146 10m/data $=! 3 \mathrm{~m} 1 ! 1 \mathrm{e} 3 ! 4 \mathrm{~m} 13 ! 1 \mathrm{~m} 7 ! 3 \mathrm{~m} 6 ! 1 \mathrm{~s} 0 \times 304 \mathrm{~d} 8 \mathrm{df} 747424 \mathrm{db} 1: 0 \times 9 \mathrm{ed} 72 \mathrm{c} 880757 \mathrm{e} 802$ !2sTail \%C3\%A2ndia!3b1!8m2!3d15.870032!4d100.992541!3m4!1s0x3124688606ed7b21:0x1f93b1 8618c1eedf!8m2!3d17.9735081!4d102.6342773>. Acesso em: 12 fev. 2018.

KIM, L. Da imitação à inovação: a dinâmica do aprendizado tecnológico da Coréia. 1ed. Campinas: Editora da UNICAMP, 2005. 392p.

PARK, J. South Korea. New York: Springer, 2012. 279p.

SHI, W. Intellectual Property in the Global Trading System - U. E. China perspective. Springer: Bangor, 2008. 333p.

SILVA, L. C. S. Modelo de Transferência de Tecnologia Verde por Intermédio dos Núcleos de Inovação Tecnológica em Institutos de Ciência e Tecnologia Brasileiros. 2016. 146f. Tese (Doutorado em Engenharia de Produção) - Escola de Engenharia, Universidade Federal do Rio Grande do Sul, Porto Alegre.

SORG. J. Thailand. In: DREXL, J.; HILTY, R.M.; SCHÖN W.; STRAUS, J. Property Intellectual in Asia: Law, Economics, History and Politics. 1ed. Stanfort: Springer, 2009. p. 303-329.

TAPLIN, R. Intellectual Property Valuation and Innovation: Towards Global Harmonisation. New York: Routledge, 2014. 180p.

THAILAND. Patent Act B.E. 2522 (1979). Thailand, 1979. [online]. Disponível em: <http://www.wipo.int/wipolex/en/profile.jsp?code=TH>. Acesso em: 15 jun. 2018.

TRADING ECONOMICS. China GDP 1960-2018. [online]. Disponível em: <https://tradingeconomics.com/china/gdp>. Acesso em: 12 jan. 2018.

TRANFIELD, D.; DENYER, D.; SMART, P. Towards a Methodology for Developing Evidence-Informed Management Knowledge by Means of Systematic Review. British Journal of Management, London, v. 14, n. 3, p. 207-222, 2003. 
YOURSTORY. The Bengal Famine: How the British Engineered the Worst Genocide in Human History for Profit. 2014. Disponível em: <https://yourstory.com/2014/08/bengalfamine-genocide/>. Acesso em: 12 jul. 2018.

WIPO. World Intellectual Property Organization. Statistical Country Profiles. Geneva, 2016. [online].

<http://www.wipo.int/ipstats/en/statistics/country_profile/profile.jsp?code=KH>. Acesso em: 08 mai. 2018.

WIPO. World Intellectual Property Organization. Statistics debase. Patent Cooperation Treaty. Geneva, 2018. [online]. Disponível em: <http://www.wipo.int/export/sites/www/treaties/en/documents/pdf/pct.pdf>. Acesso em: 16 mai. 2018.

Data de Submissão: 10/04/2020

Data de Aceite: 14/05/2020 